\title{
Mindfulness Training and Practice in Physician Assistant Education
}

\author{
Catherine K. Sadowski \\ Mercer University, sadowski_ck@mercer.edu \\ Leslie Taylor \\ Mercer University, taylor_If@mercer.edu \\ Erin Sharaf \\ Johnson \& Wales University, erin.sharaf@wju.edu
}

Follow this and additional works at: https://nsuworks.nova.edu/ijahsp

Part of the Medicine and Health Sciences Commons

\section{Recommended Citation}

Sadowski CK, Taylor L, Sharaf E. Mindfulness Training and Practice in Physician Assistant Education. The Internet Journal of Allied Health Sciences and Practice. 2021 Jan 01;19(2), Article 5.

This Manuscript is brought to you for free and open access by the College of Health Care Sciences at NSUWorks. It has been accepted for inclusion in Internet Journal of Allied Health Sciences and Practice by an authorized editor of NSUWorks. For more information, please contact nsuworks@nova.edu. 


\title{
Mindfulness Training and Practice in Physician Assistant Education
}

\begin{abstract}
Purpose: The purpose of this study was to integrate mindfulness, as a compassionate pedagogy, into a physician assistant (PA) program and assess its effects on student depression, anxiety, and stress at the conclusion of the first semester. Method: Fifty-five of 60 first-semester students provided consent. Mindfulness instruction and practice began with a six-hour intensive workshop spread over two days during the first week of the semester. This was followed by seven, brief, 10 to15 minute mindfulness practices integrated across one course. Students completed a demographic questionnaire at the beginning of the project and the DASS 21 survey which measures a range of symptoms common to depression, anxiety, and stress at weeks 1 and 16 of the semester. After the course concluded, 10 students were randomly selected from those who had identified as interested in participating in a focus group to discuss their experiences and offer suggestions for improvement. Results: DASS 21 subscale scores revealed no change in depression, anxiety, nor stress. In contrast, the focus group results revealed that student anxiety and stress levels diminished through learning about mindfulness and practicing mindful meditations. Conclusions: The incorporation of mindfulness training was generally well received by first-semester PA students. Students in the focus group reported decreased levels of anxiety and stress, while the DASS 21 revealed no change. The authors suggest that the experience could be strengthened by modifying the workshop material and extending the mindfulness practice across the didactic and clinical years to allow students more opportunities to develop their personal mindfulness practice and integrate it throughout their career.
\end{abstract}

\section{Author Bio(s)}

Catherine K. Sadowski, MHS, PA-C is a Clinical Assistant Professor at Mercer University College of Health Professions Department of Physician Assistant Studies.

Leslie F. Taylor, PT, PhD, MS is an Associate Dean and Professor at Mercer University College of Health Professions.

Erin Sharaf, MA, PA-C is a Lecturer at the Center for Physician Assistant Studies at Johnson \& Wales University. 


\title{
1IJAHSP \\ The Internet Joumnal of Allied Health Sciences and Practice \\ Dedicated to allied health professional practice and education \\ Vol. 19 No. 2 ISSN 1540-580X
}

\section{Mindfulness Training and Practice in Physician Assistant Education}

\author{
Catherine K. Sadowski \\ Leslie Taylor \\ Erin Sharaf \\ Mercer University \\ United States
}

\begin{abstract}
Purpose: The purpose of this study was to integrate mindfulness, as a compassionate pedagogy, into a physician assistant (PA) program and assess its effects on student depression, anxiety, and stress at the conclusion of the first semester. Method: Fiftyfive of 60 first-semester students provided consent. Mindfulness instruction and practice began with a six-hour intensive workshop spread over two days during the first week of the semester. This was followed by seven, brief, 10 to 15 minute mindfulness practices integrated across one course. Students completed a demographic questionnaire at the beginning of the project and the DASS 21 survey which measures a range of symptoms common to depression, anxiety, and stress at weeks 1 and 16 of the semester. After the course concluded, 10 students were randomly selected from those who had identified as interested in participating in a focus group to discuss their experiences and offer suggestions for improvement. Results: DASS 21 subscale scores revealed no change in depression, anxiety, nor stress. In contrast, the focus group results revealed that student anxiety and stress levels diminished through learning about mindfulness and practicing mindful meditations. Conclusions: The incorporation of mindfulness training was generally well received by first-semester PA students. Students in the focus group reported decreased levels of anxiety and stress, while the DASS 21 revealed no change. The authors suggest that the experience could be strengthened by modifying the workshop material and extending the mindfulness practice across the didactic and clinical years to allow students more opportunities to develop their personal mindfulness practice and integrate it throughout their career.
\end{abstract}

Keywords: mindfulness, meditation, resiliency, burnout, physician assistant, allied health 


\section{INTRODUCTION}

Students in health professions programs experience many stressors during the didactic and clinical phases of their study. Often, that stress continues in their careers due to high workloads combined with intense time pressures. Studies have shown that stress can lead to a loss of empathy and an increase in anxiety, depression, and professional burnout in healthcare providers. ${ }^{1-10}$ Finkelstein et al contend, "Stress is receiving increased attention because of the realization that tired, tense, anxious [healthcare providers] may not provide as high quality care as do those who do not suffer from these debilitating conditions."1

Similarly, professional burnout leads to negative consequences for the healthcare provider and patient in terms of job satisfaction and clinical outcomes. Barbosa et al define burnout as "a syndrome that encompasses three key components relative to healthcare providers: emotional exhaustion, depersonalization, and loss of sense of personal accomplishment in one's work."2 Evidence indicates that healthcare providers who experience burnout are prone to making errors, abandon the profession prematurely, and experience physical and psychological problems. Simultaneously, patient perceptions of the healthcare received declines.

One way to prevent these negative consequences is to teach the healthcare professional about "mindfulness." Fortney et al state, "Mindfulness is a form of mental training that enables one to attend to aspects of experience in a nonjudgmental, nonreactive way, which in turn helps cultivate clear thinking, equanimity, compassion and open-heartedness. The goal is to maintain open awareness in one's experience in a way that generates a greater sense of emotional balance and well-being. Through mindfulness practice, unhelpful habitual thought and behaviors can be recognized, allowing for new and creative ways of responding." 8

\section{Mindfulness and Compassion Training}

Mindfulness and compassion training incorporated into health education programs can instill healthy coping mechanisms to prevent physiologic and psychologic stress which often leads to burnout in healthcare providers during their educational training and careers. A study conducted by Pace et al, included sixty-one adults who were randomly assigned to 6 weeks of training in compassion meditation $(n=33)$ or participation in a health discussion control group $(n=28)$. The groups were then exposed to a standardized laboratory stressor (Trier social stress test [TSST]). Responses to the TSST were determined by repeated assessments of plasma concentrations of interleukin (IL)-6 and cortisol as well as total distress scores on the Profile of Mood States (POMS) measured in each group."11 The meditation group had decreased TSST-induced IL-6 and POMS distress scores. The researchers concluded that compassion meditation correlated with reduced immune and behavioral responses instigated by stress.

In another study, Lutz et al examined the regulation of neural circuitry of emotion in those experiencing compassion meditation. They considered if novice and expert meditation practitioners could impact brain neural circuitry similar to impacts seen with attentional and motor-sensory skills training, as evidenced by functional magnetic resonance imaging. The meditation groups demonstrated increased activation in the amygdala, right temporo-parietal junction (TPJ), and right posterior superior temporal sulcus (pSTS) supporting the hypothesis that meditative practices can alter the neural circuitry. ${ }^{12}$

These studies provide evidence that compassion meditation can produce physiologic and emotional changes in human beings, and therefore, might be used to combat stress and burnout in healthcare professionals.

\section{Mindfulness and Healthcare Education}

Healthcare education needs effective strategies to combat compassion fatigue and anxiety leading to burnout. Implementing mindfulness training and exploring its impact on PA students' experiences is one strategy worth examination. Studies examining mindfulness training in relation to medical students and physicians have shown that medical students and physicians who engaged in mindfulness practices experienced decreased stress and an improvement in their quality of life. 1,5,7,8, 13,14

In contrast, there has been much less published on the effects of mindfulness on PA students. One study included 13 graduate healthcare students in podiatric medicine, physician assistant, physical therapy, occupational therapy, and graduate nursing. While it is important to recognize that this study included PA students the sample size was small with a total of 13 students in the experimental group and 15 in the control group, only 5 of whom were PA students. ${ }^{2}$ In comparison, Hoover et al examined mindfulness and decentering training in a PA curriculum providing a robust sample size of 90 PA students. In this study, the authors demonstrated a positive relationship between increasing levels of mindfulness and changes in student life satisfaction and stress. ${ }^{15}$

In terms of burnout, there is a limited amount of literature focused on PA student and professional PA burnout. ${ }^{16-19}$ Even though this literature identifies the reality of burnout within the profession, it does not offer a solution to the problem. Mindfulness pedagogy can be one solution, and therefore, needs to be studied objectively with more published peer reviewed data and analysis. 
Given the current state of healthcare nationally, PAs are under ever more increasing stress. The U.S. is facing an enormous primary care shortage. ${ }^{20}$ According to Fortney et al, burnout "is more common among physicians than among other professionals, with specialties on the front lines such as primary care being at greatest risk." ${ }^{8}$ Compounding this problem is the fact that "the total number of office visits to primary care physicians is projected to increase from 462 million in 2008 to 565 million in 2025. After incorporating insurance expansion, the United States will require nearly 52,000 additional primary care physicians by $2025 . "{ }^{21}$ To fill this vacuum, the U.S. Department of Health and Human Services predicts, "...the supply of PAs is expected to grow by 25,380 FTEs - from 33,390 FTEs in 2013 to 58,770 FTEs in 2025 - a 76 percent increase."22 What can be extrapolated from these forecasts is that PAs will be working on the front lines filling healthcare shortages, and therefore, are at a high risk for experiencing professional and personal stress. These projections reinforce the necessity to implement mindfulness into PA education in order to prepare students in learning the art of self-awareness and emotion management. Furthermore, it highlights the need to study the impact of mindfulness training on PA students.

The application of mindfulness in the PA classroom and its outcomes on student depression, anxiety, and stress is applicable and timely for all healthcare education programs. The national health care trends not only impact the physician assistant, but also other healthcare providers, including physical therapists, psychologists, pharmacists, and nurses. One commonality shared among these professions is the foundation upon which we teach all health care professional students - how we inspire, foster, and develop entrylevel providers is critical to our core missions. In this regard, the information gained from the application of mindfulness in a PA curriculum is applicable to allied health educational programs.

The purpose of this project was to integrate mindfulness, as a compassionate pedagogy, into the Mercer University PA curriculum and assess its effects on student depression, anxiety, and stress at the conclusion of the first semester. The authors hypothesized that students would report reductions in depression, anxiety, and stress upon completion of the project.

\section{METHODOLOGY}

\section{Subjects}

The Mercer University IRB approved this study (H1611314). Participants included newly matriculated PA students at the beginning of their didactic education. Students were informed that their participation in the study was voluntary and fifty-five of sixty first-year physician assistant students provided signed consent.

Seventy three percent of the participants identified as female and the participants ranged in age from 21 to 58 years, with an average age of 26 . Eighty-nine percent (89\%) identified as currently engaging in some form of regular exercise, and $49 \%$ identified as having some experience with mindfulness, guided imagery, relaxation techniques, yoga, or meditation.

\section{Design}

The study used a single sample, non-experimental descriptive design. At program orientation, prior to the start of the semester, all 60 students received an introduction to the study including voluntary participation in the practice sessions, explanation of data collection through an anonymous survey, and optional participation in a focus group discussion after the first semester's end. Mindfulness instruction and practice began with a 6-hour intensive workshop held over two days during the first week of the semester. All students were required to attend this introductory workshop whether or not they participated in the study, as it was embedded within an existing course. The mindfulness workshop was facilitated by the third author, a physician assistant wellversed in mindfulness practice and education. During the workshop, students were instructed on physiological aspects of acute and chronic stress on the immune system as well as neurologic cognition. Mind-body connections and effects on perception, memory, thought process, and behavior were explored.

Students were instructed in three meditation practices modeled from the Mind Body Stress Reduction (MBSR) program developed by Jon Kabat-Zinn, Ph.D., at the University of Massachusetts Medical Center. During the semester, the primary author and course director led the students in seven, brief 10-15 minute mindfulness practices integrated across the course. Practice occurred at the beginning of two lectures spaced between four practical examinations and one written examination. Students who had elected not to participate in the study were excused from participation. The following three meditations were performed throughout the course:

1. Mindful meditation consists of focusing on the breath while noticing sensations (sights, sounds, smells) that routinely are missed in one's busy daily life. The practice can be applied during times of heightened stress. Through strengthening present-moment awareness, one understands that emotion, which often is associated with negative self-perception, is transitory and does not define a person. This practice also hones attention and focus. 
2. The loving-kindness meditation involves first expressing gratitude and appreciation toward oneself, then to a friend, then to a person who may be perceived as threatening, and then ultimately to others outside the immediate circle. This practice strengthens compassion and empathy.

3. "Mindful Walking" is the practice of walking quietly, consciously connected to the earth with compassion, present each moment by inviting the physical sensations of walking to be the focus of awareness. This practice is different from walking to accomplish a means to an end. Through the practice of mindful walking, one learns that the mindfulness and the associated qualities can be experienced at any time through how we engage with everyday activities. In the long run, this sense of peace can create a larger feeling of connectivity to a community larger than oneself.

The authors purposely designed the schedule with the dual goal of strengthening focus, empathy, and inner peace thereby reducing anxiety, depression, and stress. After the course concluded, 10 students were randomly selected from those who had identified as interested in participating in a focus group to discuss their experiences and offer suggestions for improvement.

\section{Instruments and Data Collection}

On the first day of class, participants completed a researcher-developed demographic questionnaire, followed by the Depression Anxiety Stress Scale 21 (DASS 21) (See Appendix). The DASS 21 is a shorter version of the original 42-item DASS questionnaire. Both are self-report questionnaires designed to measure the negative emotional states of depression, anxiety, and stress. Subjects are asked to use 4-point severity/frequency scales from 0 (did not apply to me over the past week) to 3 (applied very to me over the past week) to rate the extent to which they have experienced each state over the past seven days. The DASS 21 survey was administered again at the conclusion of the course (week 16). Three weeks after the course ended, participants were asked if they were willing to contribute their thoughts in a one-hour focus group the following week. From the list of volunteers, ten students were randomly selected to engage in a focus group (week 20). The focus group was facilitated by the second author, an academic professional with experience leading focus groups. The facilitator had no prior contact with the students. The course director did not participate in the focus group to minimize bias to influence the student responses.

\section{Data Analysis}

DASS 21 scores for depression, anxiety, and stress were calculated following the survey instructions. Summed scores of the relevant items for each subscale were multiplied by two for comparison with published DASS ranges. Data were analyzed using descriptive statistics and assessment of changes over time of scores on the DASS 21 survey. Evaluative data using focus group methodology were compiled.

\section{RESULTS}

Group means of DASS 21 subscale scores, displayed in Table 1, did not change over the course of the semester when considering categorical norms. Depression scores remained in the normal range, and anxiety and stress subscales remained in the mild range.

Table 1. DASS 21 Scores for Depression, Anxiety, and Stress

\begin{tabular}{|l|l|l|l|}
\hline & \multicolumn{1}{|c|}{ Pre } & \multicolumn{1}{c|}{ Post } & \multicolumn{1}{c|}{ Categorical Norm } \\
\hline DASS 21 (depression) & 3.58 & 5.10 & Normal \\
\hline DASS 21 (anxiety) & 6.24 & 6.18 & Mild \\
\hline DASS 21 (stress) & 11.86 & 12.50 & Mild \\
\hline
\end{tabular}

\section{Focus Group Consensus}

The focus group data proved insightful. Unlike the DASS 21 data, the focus group reported a change in the level of anxiety and stress. Students identified ways that regular mindful practice had diminished their levels of anxiety and stress. Summary statements are provided for the workshop and the classroom components of the implementation, and for benefits and behavior changes resulting from mindfulness practice.

\section{Workshop Considerations}

\section{Workshop Considerations: Format/Length}

The group identified options to improve the format / length of the workshop. The workshop occurred over 6 hours during the first week of the program. Students suggested that one 4-hour workshop would have been preferable with either an additional seminar (a refresher day) later in the semester or follow-up meetings threaded throughout the semester in shorter chunks of time. Another confounding variable was that the students' white coat ceremony occurred on the afternoon of the second day of the workshop. The excitement of the impending ceremony was a big distraction, and students suggested not holding a mindfulness training session on that day. 


\section{Workshop Considerations: Placement}

All agreed that the timing of the workshop was good on several levels. Students appreciated that the workshop was among their first experiences as a Mercer PA student, as they felt that the program valued the topic as well as their own mental health.

\section{Workshop Considerations: Content}

Addressing placement and content, the application of mindfulness practice for anxiety as a new PA student was positive. Some strategies (thoughts that help you, thoughts that hurt you) were particularly useful as the semester progressed. The students valued information provided by the facilitator about the benefits of mindfulness for patients. Students commented that the longer meditations were too long for beginners and were even too much for those who regularly engaged in practice. Students found the PowerPoint presentation helpful and felt that reminders to review it were warranted.

\section{Workshop Considerations: Historical and Scientific Background}

The participants appreciated the historical and scientific presentation on mindfulness. They desired more depth in the physiological responses as they noted immediate personal and professional application. They appreciated having an alternative tool for their clinical tool bag. Participants noted that this would be especially beneficial if the second day of the workshop occurred later in the semester after having taken classes which address the neurophysiology of pain. The students asked for consideration of incorporating the mindfulness concepts into their pathophysiology (and other) classes.

\section{Workshop Considerations: Religious Implications}

No religious conflicts were identified, and all felt that the material could be framed through a secular, spiritual, or religious lens. The facilitator's presentation allowed each class member to determine the degree to which mindfulness practice correlated with their own religious/spiritual beliefs. This was viewed as a plus.

\section{Workshop Considerations: Moments of Connection and Disconnection}

The participants appreciated that the program valued mindfulness, and that the program was progressive in implementing an alternative practice of which most students were aware. Students felt connected to others in their class and to the program as they learned about strategies to implement to control their own anxiety and stress. Participants voiced feeling empowered by the recognition that thoughts can "help us or hurt us" in PA school and life. Students also commented on mindfulness practice as a tool for patients.

The length of the mindfulness exercises, especially for beginners, were too long. The length (too much/too long) turned off some of the participants who had prior experience with mindfulness, and this was deemed problematic by the group - if they were tuned out, what about those for whom this was their first exposure?

\section{Course Considerations \\ Course Considerations: Interspersed Practice}

The students liked having the opportunity to practice during a class but recommended scheduling the practice times. Part of mindfulness is being prepared for it and being at a place to accept it, so the suddenness of the practices were challenging at times. Students said that scheduling it would assist in preparing for the practice mentally, and practically as well (e.g. wouldn't be in heels for a "walking meditation" on the field).

\section{Course Considerations: Length /Placement}

The shorter practice sessions (10-15 minutes) and the placement in the class (beginning of class and at periodic intervals) were viewed positively. The students enjoyed the meditations in class; however, they would not recommend placing a practice right before a test.

\section{Course Considerations: Freedom to Abstain}

While it was always made clear that participation was optional, classmates did not feel free to abstain. Two reasons posed included not wanting to appear disrespectful, and feeling uncomfortable with doing something different or leaving the room.

\section{Course Considerations: Content}

When providing opportunities for class practice, the students recommended adding more science and evidence-based medicine to support the practice and the integration of medical psychology. Regarding the three practice activities, students viewed silent mindful meditations favorably. The use of the bell helped them bring their attention back. The guided loving kindness meditations were very helpful, especially for beginners. Mindful movement meditations, while feeling a little self-conscious at times, especially 
around others in the class who were not practicing, were also viewed positively. The nonjudgmental way that the class was divided during one walking meditation was helpful (those who are practicing walk here versus those who want to walk and talk there.)

\section{Benefits and Behavior Change Benefits}

Students identified ways that regular practice had changed their anxiety and stress levels. Examples included using the techniques to help with falling asleep (from someone who had never practiced before) and using the techniques to identify negative thoughts (let them be/let them go - those that do not benefit me...), finding and using new apps (such as the Calm app that has 10 minute or less meditations). As a physician assistant student and practitioner, participants saw benefits for calming and letting thoughts go. All agreed that it could change their anxiety level.

\section{Patient Care}

Several commented on wanting to learn more about mindfulness in order to be more effective with their patients. They felt that these techniques could assist in their connectedness to their patients in a nonjudgmental way. This perception increased after the semester of practice, and helped the students view patients from a holistic perspective.

\section{Continued Integration}

Students recommended continued integration of the material in the program with the recommended modifications: integration of the material into other modules, integration of the science behind mindfulness across body systems with techniques as possible interventions or presented as clinical pearls, and inclusion of other professors into the workshop for those who are incorporating mindfulness into their classes.

\section{DISCUSSION}

The purpose of this project was to integrate mindfulness, as a compassionate pedagogy, into a PA curriculum and assess its effects on student depression, anxiety, and stress at the conclusion of the first semester. The authors hypothesized that study outcomes would reveal reductions in depression, anxiety, and stress. The results were mixed, as students in the focus group identified that their anxiety and stress were lowered by practice; however, the DASS 21 revealed no change. The DASS 21 is based on a dimensional rather than a categorical conception of a psychological disorder.

One explanation to the DASS 21 results was that the mindfulness training and meditation practices proved ineffective. Alternatively, the authors wondered if the timing of the final DASS 21 data collection may have skewed the results. When the students completed the final survey, they were in the midst of preparing for final exams which is usually a period of intense anxiety. As a result, this could have negated any incremental positive change developed over the course of the first semester at the conclusion of the semester. In the focus group, students also identified that the timing of the surveys may have skewed results, as everyone was so excited and upbeat at the beginning of the semester and so stressed for finals.

Another factor important to consider was the ambitious study design. Meditation is an active process which many argue requires disciplined practice over months to years to reap the benefits. Perhaps the duration of the mindfulness training and practices were suboptimal. Spreading the content throughout various courses over several semesters rather than one semester might have proved more impactful.

The qualitative data proved to be rich in insight. The authors were surprised by how receptive students were to mindfulness training. The focus group participants expressed gratitude for the training which was characterized as "alternative" and "progressive." Prior to initiating the study, the authors feared that the students might resent or reject the novel content added to an already full curriculum. Participants also appreciated the intentional placement of the mindfulness workshop during the first week of the semester to help alleviate ensuing anxiety and stress which PA students inevitably experience during the didactic year.

The focus group also provided future recommendations to improve the training. One suggestion related to shortening the duration of the guided meditations to better hold the students' attention. They also recommended that the training be distributed across courses to align with pathophysiologic and psychologic didactic material. And, in contrast to the DASS 21 data, the focus group purported improvements in anxiety and stress levels over the course of the semester. Students also expressed value in recognizing emotions, whether they be "good" or "bad," as ephemeral versus self-defining.

The timing of the workshop scheduled at the genesis of the students' semester was intentional. It was essential that the student gain exposure to the philosophy and practice of mindfulness from the outset so that they could continue the practices while confronting challenging academic and personal situations. As the course intensified and students' predicted levels of stress 
increased, they would build upon the mindful foundation presented in order to maintain a mental equilibrium. At the same time, the students would expand inner levels of compassion and kindness.

Teaching 'Mindfulness' may enhance the PA student's learning experience and instill healthy coping mechanisms to prevent a decline in empathy and rise in anxiety. Marga Odahowski explains that,

\begin{abstract}
Mindfulness is training the mind to be present in the moment. [It is] a keen and compassionate awareness. Focusing attention to the present brings increasing awareness, connection, and acceptance. Investigating and training the mind to [foster] a clear awareness is the cornerstone of mindfulness in higher education. Learning...is not simply [through] memorization of theory or facts. Paying attention means listening deeply to ourselves (our thoughts, feelings, emotions, and tendencies) as well as to others. It is important to cultivate compassion and listen with a gentle ear of self-acceptance. Not judging the self or others. Simply through acceptance and observation one can make room for new and different choices. As you step into an authentic life to understand that pain is a condition of life and your values of inner freedom, equanimity and community allow you the full expression of suffering as well as joy. Coming to know yourself fully you also come to understand the absolute worth of every human being. ${ }^{23}$
\end{abstract}

It is interesting to compare and contrast this study to the one other published study focused on mindfulness in PA education conducted by Hoover et al. Similarities include the introduction of the interventions at the beginning of their respective programs, focus on PA students, and recognition of clinician burnout and need for strategies to prevent it. What is a notable difference are the mindful practices applied in the two studies. This study focused on an introductory mindfulness workshop followed by three forms of meditation whereas the other study included "reflective writing assignments, daily home practice of decentering, and mindful breathing". ${ }^{15}$

Questions as to the best methods to present mindfulness in healthcare programs necessitates future studies. The authors would argue that in order to answer these questions, studies will need to be conducted not only during the didactic year of a PA program, but also the clinical year. Follow-up on these students after graduation would assist in determining long-term effects. And, these studies would benefit from a multi-institutional format. The implications of these findings would be valuable for the PA profession (educators, students, clinicians) and allied health professionals who work on the frontlines in the healthcare system.

\title{
Limitations
}

This study had several limitations. The duration of the project only encompassed one semester. To understand the meaning of "mindfulness" requires time and practice. As medical educators, we often use the expression, "See one, do one, teach one" to denote the process of "hands-on" skill mastery. In reflecting on the project, the authors realize that the design aimed to accomplish those three concepts over one semester. Unlike teaching a "hands-on" skill which can be learned relatively quickly, mindfulness lends itself to teaching, practicing, and reflecting over longer or more concentrated periods of time.

Additional limitations include a small sample size and the duration of the individual meditation practices. The timing of survey distribution measuring students' anxiety and stress may have skewed the results. Consideration of survey instruments should also be considered. Replacing the DASS 21 evaluation tool with the DASS tool might have provided a more in depth analysis.

\section{CONCLUSION}

Information collected from the focus group provided suggestions for improvements in the workshop and classroom implementation, insights into personal and professional benefits, and support for continued inclusion in the program. Mindfulness is a valuable pedagogy to support the holistic development of healthcare providers. The health care student who cultivates awareness and mindful focus will be armed with techniques to learn more effectively, treat patients more humanely, and make better clinical decisions. And in so doing, the student can sustain a sense of well-being throughout their graduate education extending into their career. 


\section{References}

1. Finkelstein C, Brownstein A, Scott C, Lan Y-L. Anxiety and stress reduction in medical education: an intervention. Med Educ. 2007;41(3):258-264. doi:10.1111/j.1365-2929.2007.02685.x

2. Barbosa P, Raymond G, Zlotnick C, Wilk J, Toomey R, Mitchell J. Mindfulness-based stress reduction training is associated with greater empathy and reduced anxiety for graduate healthcare students. Educ Health Abingdon Engl. 2013;26(1):9-14. doi:10.4103/1357-6283.112794

3. Dahlin M, Joneborg N, Runeson B. Performance-based self-esteem and burnout in a cross-sectional study of medical students. Med Teach. 2007;29(1):43-48. doi:10.1080/01421590601175309

4. Factors at medical school and work related to exhaustion among physicians in their first postgraduate year. Accessed October 4, 2016. http://www.medscape.com/medline/abstract/20429747

5. Rosenzweig S, Reibel DK, Greeson JM, Brainard GC, Hojat M. Mindfulness-based stress reduction lowers psychological distress in medical students. Teach Learn Med. 2003;15(2):88-92. doi:10.1207/S15328015TLM1502_03

6. Bhutani J, Bhutani S, Balhara YPS, Kalra S. Compassion Fatigue and Burnout Amongst Clinicians: A Medical Exploratory Study. Indian J Psychol Med. 2012;34(4):332-337. doi:10.4103/0253-7176.108206

7. Dobkin PL, Hutchinson TA. Teaching mindfulness in medical school: where are we now and where are we going? Med Educ. 2013;47(8):768-779. doi:10.1111/medu.12200

8. Fortney L, Luchterhand C, Zakletskaia L, Zgierska A, Rakel D. Abbreviated mindfulness intervention for job satisfaction, quality of life, and compassion in primary care clinicians: a pilot study. Ann Fam Med. 2013;11(5):412-420. doi:10.1370/afm.1511

9. Epstein R, Quill T, Krasner M, Mcdonald S. A Curriculum in Mindful Practice for Students and Residents Faculty Manual. ResearchGate. Accessed October 4, 2016. https://www.researchgate.net/publication/265539168_A_Curriculum_in_Mindful_Practice_for_Students_and_Residents_F aculty_Manual

10. Hojat M, Mangione S, Nasca TJ, et al. An empirical study of decline in empathy in medical school. Med Educ. 2004;38(9):934-941. doi:10.1111/j.1365-2929.2004.01911.x

11. Pace TWW, Negi LT, Adame DD, et al. Effect of compassion meditation on neuroendocrine, innate immune and behavioral responses to psychosocial stress. Psychoneuroendocrinology. 2009;34(1):87-98. doi:10.1016/j.psyneuen.2008.08.011

12. Lutz A, Brefczynski-Lewis J, Johnstone T, Davidson RJ. Regulation of the Neural Circuitry of Emotion by Compassion Meditation: Effects of Meditative Expertise. Baune B, ed. PLoS ONE. 2008;3(3):e1897. doi:10.1371/journal.pone.0001897

13. Krasner MS. Association of an Educational Program in Mindful Communication With Burnout, Empathy, and Attitudes Among Primary Care Physicians. JAMA. 2009;302(12):1284. doi:10.1001/jama.2009.1384

14. Raab K, Sogge K, Parker N, Flament MF. Mindfulness-based stress reduction and self-compassion among mental healthcare professionals: a pilot study. Ment Health Relig Cult. 2015;18(6):503-512. doi:10.1080/13674676.2015.1081588

15. Hoover EB, Butaney B, Stoehr JD. Exploring the Effectiveness of Mindfulness and Decentering Training in a Physician Assistant Curriculum: J Physician Assist Educ. 2020;31(1):19-22. doi:10.1097/JPA.0000000000000288

16. Benson MA, Peterson T, Salazar L, et al. Burnout in Rural Physician Assistants: An Initial Study. J Physician Assist Educ Off J Physician Assist Educ Assoc. 2016;27(2):81-83. doi:10.1097/JPA.0000000000000069

17. Bell RB, Davison M, Sefcik D. A first survey. Measuring burnout in emergency medicine physician assistants. JAAPA Off J Am Acad Physician Assist. 2002;15(3):40-42, 45-48, 51-52 passim.

18. Orozco JM, Furman JA, Roman C, Guthrie J, Jackson C. Burnout prevalence in PA students: J Am Acad Physician Assist. 2016;29(10):1. doi:10.1097/01.JAA.0000490115.04561.27

19. Johnson AK, Blackstone SR, Simmons W, Skelly A. Assessing Burnout and Interest in Wellness Programs in Physician Assistant Students: J Physician Assist Educ. 2020;31(2):56-62. doi:10.1097/JPA.0000000000000303

20. Porter S. Significant Primary Care, Overall Physician Shortage Predicted by 2025. Accessed October 4, 2016. http://www.aafp.org/news/practice-professional-issues/20150303aamcwkforce.html

21. Petterson SM, Liaw WR, Phillips RL, Rabin DL, Meyers DS, Bazemore AW. Projecting US Primary Care Physician Workforce Needs: 2010-2025. Ann Fam Med. 2012;10(6):503-509. doi:10.1370/afm.1431

22. National and Regional Projections of Supply and Demand for Primary Care Practitioners: 2013-2025. Published online 2016.

23. Odahowski M. Mindfulness in Higher Education. Social Science/Psychology. Published Fall 2004. Accessed October 23 , 2016. https://studylib.net/doc/14208861/marga-odahowski---fall-2004---1-- 


\section{APPENDIX: Depression Anxiety Stress Scale (DASS 21)}

\begin{tabular}{|c|c|c|c|c|}
\hline Question & \multicolumn{4}{|c|}{ Response } \\
\hline $\begin{array}{l}\text { Please read each statement and circle a number } \\
0,1,2 \text { or } 3 \text { which indicates how much the } \\
\text { statement applied to you over the past week. } \\
\text { There are no right or wrong answers. Do not } \\
\text { spend too much time on any statement. }\end{array}$ & $\begin{array}{l}\text { D } \\
\text { Did not apply to } \\
\text { me at all- } \\
\text { NEVER }\end{array}$ & $\begin{array}{l}1 \\
\text { Applied to me } \\
\text { to some } \\
\text { degree, or } \\
\text { some of the } \\
\text { time -- } \\
\text { sOMETIMES }\end{array}$ & $\begin{array}{l}2 \\
\text { Applied to me } \\
\text { to a } \\
\text { considerable } \\
\text { degree, or a } \\
\text { good part of } \\
\text { time - OFTEN }\end{array}$ & $\begin{array}{l}3 \\
\text { Applied to me } \\
\text { very much, or } \\
\text { most of the } \\
\text { time - } \\
\text { ALMOST } \\
\text { ALWAYS }\end{array}$ \\
\hline Q1. I found it hard to wind down & & & & \\
\hline Q2. I was aware of dryness of mouth & & & & \\
\hline $\begin{array}{l}\text { Q3. I couldn't seem to experience any positive } \\
\text { feeling at all }\end{array}$ & & & & \\
\hline $\begin{array}{l}\text { Q4. I experienced breathing difficulty (e.g., } \\
\text { excessively rapid breathing, breathlessness in the } \\
\text { absence of physical exertion) }\end{array}$ & & & & \\
\hline $\begin{array}{l}\text { Q5. I found it difficult to work up the initiative to do } \\
\text { things }\end{array}$ & & & & \\
\hline Q6. I tended to over-react to situations & & & & \\
\hline Q7. I experienced trembling (e.g., in the hands) & & & & \\
\hline Q8. I felt that I was using a lot of nervous energy & & & & \\
\hline $\begin{array}{l}\text { Q9. I was worried about situations in which I might } \\
\text { panic and make a fool of myself }\end{array}$ & & & & \\
\hline Q10. I felt that I had nothing to look forward to & & & & \\
\hline Q11. I found myself getting agitated & & & & \\
\hline Q12. I found it difficult to relax & & & & \\
\hline Q13. I felt down-hearted and blue & & & & \\
\hline $\begin{array}{l}\text { Q14. I was intolerant of anything that kept me } \\
\text { from getting on with what I was doing }\end{array}$ & & & & \\
\hline Q15. I felt I was close to panic & & & & \\
\hline $\begin{array}{l}\text { Q16. I was unable to become enthusiastic about } \\
\text { anything }\end{array}$ & & & & \\
\hline Q17. I felt I wasn't worth much as a person & & & & \\
\hline Q18. I felt that I was rather touchy & & & & \\
\hline $\begin{array}{l}\text { Q19. I was aware of the action of my heart in the } \\
\text { absence of physical exertion (e.g., sense of heart } \\
\text { rate increase, heart missing a beat) }\end{array}$ & & & & \\
\hline Q20. I felt scared without any good reason & & & & \\
\hline Q21. I felt that life was meaningless & & & & \\
\hline
\end{tabular}

